\title{
Effect of an Intensive Weight-Loss Lifestyle Intervention on Kidney Function: A Randomized Controlled Trial
}

\author{
Andrés Díaz-López ${ }^{a, b, c, d}$ Nerea Becerra-Tomás ${ }^{a, b, c, d}$ Verónica Ruiz ${ }^{a, b, c}$ Estefania Toledo ${ }^{\text {d,e }}$ \\ Nancy Babio ${ }^{a}, b, c, d$ Dolores Corella ${ }^{d, f}$ Montse Fitó ${ }^{d, g}$ Dora Romaguera ${ }^{d, h}$ Jesús Vioque ${ }^{i, j}$ \\ Ángel M. Alonso-Gómez ${ }^{\mathrm{d}, \mathrm{k}}$ Julia Wärnberg ${ }^{\mathrm{d}, \mathrm{l}} \quad$ J. Alfredo Martínez ${ }^{\mathrm{d}, \mathrm{m}, \mathrm{n}}$ Luís Serra-Majem $^{\mathrm{d}, \mathrm{o}}$ \\ Ramon Estruch $^{d, p}$ Francisco J. Tinahones ${ }^{d, q}$ José Lapetra ${ }^{d, r}$ Xavier Pintó ${ }^{d, s}$ Josep A. Tur ${ }^{d, h, t}$ \\ José López-Miranda ${ }^{\mathrm{d}, \mathrm{u}}$ Naomi Cano Ibañez ${ }^{\mathrm{j}, \mathrm{v}}$ Miguel Delgado-Rodríguez ${ }^{\mathrm{j}, \mathrm{w}}$ Pilar Matía-Martín ${ }^{\mathrm{d}, \mathrm{x}}$

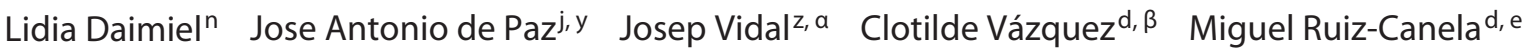 \\ Mònica Bullóa, b, c, d José V. Sorlí ${ }^{d, f} \quad$ Albert Goday $^{d, g}$ Miquel Fiold, $^{d}$ Manoli García-de-la-Hera ${ }^{i, j}$ \\ Lucas Tojal Sierrad, $\mathrm{k}$ Napoleón Pérez-Farinós ${ }^{\mathrm{d}, \mathrm{\gamma}}$ Maria Ángeles Zulet ${ }^{\mathrm{d}, \mathrm{m}}$ \\ Almudena Sánchez-Villegas ${ }^{d, o}$ Emilio Sacanella ${ }^{d, p}$ José Carlos Fernández-García ${ }^{d, q}$ \\ José Manuel Santos-Lozano $^{\mathrm{d}, \mathrm{r}}$ Miquel Gimenez-Graciad, $\mathrm{s}$ Maria del Mar Bibilonid, $\mathrm{h}, \mathrm{t}$ \\ Javier Diez-Espino ${ }^{d, e} \quad$ Carolina Ortega-Azorin ${ }^{d, f}$ Olga Castañer ${ }^{d, g}$ Marga Morey ${ }^{d, h}$ \\ Laura Torres-Collado ${ }^{i, j}$ Carolina Sorto Sanchez ${ }^{d, k}$ Miguel Ángel Muñoz ${ }^{d, g}$ Emilio Ros ${ }^{d, \delta}$
} Miguel A. Martinez-Gonzalez ${ }^{\mathrm{d}, e, \varepsilon}$ Jordi Salas-Salvadóa, b, c, d the PREDIMED-Plus Investigators

aDepartament de Bioquímica i Biotecnologia, Unitat de Nutrició, Universitat Rovira i Virgili, Reus, Spain; ${ }^{\text {Institut }}$ d'Investigació Sanitària Pere Virgili (IISPV), Reus, Spain; 'Nutrition Unit, University Hospital of Sant Joan de Reus, Reus, Spain; 'Centro de Investigación Biomédica en Red Fisiopatología de la Obesidad y la Nutrición (CIBEROBN), Institute of Health Carlos III, Madrid, Spain; 'Department of Preventive Medicine and Public Health, IdiSNA, University of Navarra, Pamplona, Spain; 'Department of Preventive Medicine, University of Valencia, Valencia, Spain; 9 Cardiovascular Risk and Nutrition research group (CARIN), Hospital del Mar Research Institute (IMIM), Barcelona, Spain; hHealth Research Institute of the Balearic Islands (IdISBa), Palma de Mallorca, Spain; 'ISABIAL-FISABIO, Miguel Hernandez University, Alicante,

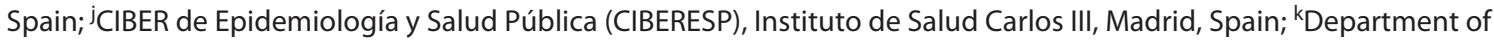
Cardiology, Organización Sanitaria Integrada (OSI) ARABA, University Hospital Araba, Vitoria-Gasteiz, Spain; 'Department of Nursing, Institute of Biomedical Research in Malaga (IBIMA), University of Málaga, Málaga, Spain; ${ }^{\mathrm{m} D e p a r t m e n t ~ o f ~}$

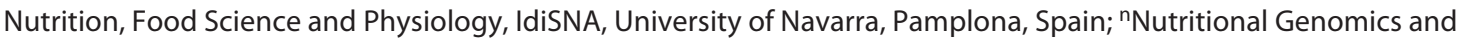
Epigenomics Group, IMDEA Food, CEI UAM + CSIC, Madrid, Spain; ${ }^{\circ}$ Research Institute of Biomedical and Health Sciences (IUIBS), University of Las Palmas de Gran Canaria, Preventive Medicine Service, Centro Hospitalario Universitario

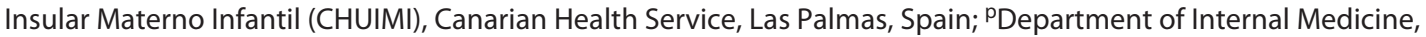
Institutd'Investigacions Biomèdiques August Pi Sunyer (IDIBAPS), Hospital Clinic, University of Barcelona, Barcelona, Spain; ${ }^{9}$ Department of Endocrinology, Instituto de Investigación Biomédica de Málaga (IBIMA), Virgen de la Victoria Hospital, University of Málaga, Málaga, Spain; 'Department of Family Medicine, Research Unit, Distrito Sanitario Atención Primaria Sevilla, Sevilla, Spain;

List of PREDIMED-Plus study investigators (online suppl. appendix).

Trial registration: this study was registered at the International Standard Randomized Controlled Trial. isrctn.com Identifier: ISRCTN89898870. Registration date: July 24, 2014 - retrospectively registered.

karger@karger.com www.karger.com/ajn

(c) 2021 S. Karger AG, Base

Karger!
Jordi Salas-Salvadó

Human Nutrition Unit, Faculty of Medicine and Health Sciences Universitat Rovira i Virgili, C/Sant Llorenç 21 ES-43201 Reus (Spain)

jordi.salas@urv.cat 
'Lipids and Vascular Risk Unit, Internal Medicine, Hospital Universitario de Bellvitge, Hospitalet de Llobregat,

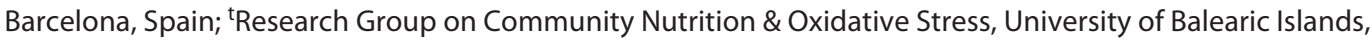
Palma de Mallorca, Spain; "Department of Internal Medicine, Maimonides Biomedical Research Institute of Cordoba (IMIBIC), Reina Sofia University Hospital, University of Cordoba, Cordoba, Spain; ${ }^{\vee}$ Department of Preventive Medicine, University of Granada, Granada, Spain; 'Division of Preventive Medicine, Faculty of Medicine, University of Jaén, Jaén, Spain; ${ }^{x}$ Department of Endocrinology and Nutrition, Instituto de Investigación Sanitaria Hospital Clínico San Carlos (IdISSC), Madrid, Spain; ' Y Institute of Biomedicine (IBIOMED), University of León, León, Spain; ${ }^{z}$ Departament of Endocrinology, IDIBAPS, Hospital Clínic, University of Barcelona, Barcelona, Spain; ${ }^{a} \mathrm{CIBER}$ Diabetes y Enfermedades Metabólicas (CIBERDEM), Instituto de Salud Carlos III (ISCIII), Madrid, Spain; ${ }^{\beta}$ Department of Endocrinology and Nutrition, Hospital Fundación Jimenez Díaz, Instituto de Investigaciones Biomédicas IISFJD, University Autonoma, Madrid, Spain; ' $D$ Department of Public Health, University of Málaga, Institute of Biomedical Research in Malaga (IBIMA), Málaga, Spain; 'Lipid Clinic, Department of Endocrinology and Nutrition, Institut d'Investigacions Biomèdiques August Pi Sunyer (IDIBAPS), Hospital Clínic, Barcelona, Spain; ' Department of Nutrition, Harvard T.H. Chan School of Public Health, Boston, MA, USA

\section{Keywords}

Dietary intervention $\cdot$ Kidney function $\cdot$ Mediterranean diet . Weight loss · Glomerular filtration rate · PREDIMED-Plus

\begin{abstract}
Introduction: Large randomized trials testing the effect of a multifactorial weight-loss lifestyle intervention including Mediterranean diet (MedDiet) on renal function are lacking. Here, we evaluated the 1 -year efficacy of an intensive weightloss intervention with an energy-reduced MedDiet (erMedDiet) plus increased physical activity (PA) on renal function.
\end{abstract} Methods: Randomized controlled "PREvención con Dleta MEDiterránea-Plus" (PREDIMED-Plus) trial is conducted in 23 Spanish centers comprising 208 primary care clinics. Overweight/obese $(n=6,719)$ adults aged $55-75$ years with metabolic syndrome were randomly assigned (1:1) to an intensive weight-loss lifestyle intervention with an erMedDiet, PA promotion, and behavioral support (intervention) or usualcare advice to adhere to an energy-unrestricted MedDiet (control) between September 2013 and December 2016. The primary outcome was 1-year change in estimated glomerular filtration rate (eGFR). Secondary outcomes were changes in urine albumin-to-creatinine ratio (UACR), incidence of moderately/severely impaired eGFR $\left(<60 \mathrm{~mL} / \mathrm{min} / 1.73 \mathrm{~m}^{2}\right)$ and micro- to macroalbuminuria (UACR $\geq 30 \mathrm{mg} / \mathrm{g}$ ), and reversion of moderately ( 45 to $<60 \mathrm{~mL} / \mathrm{min} / 1.73 \mathrm{~m}^{2}$ ) to mildly impaired GFR ( 60 to $<90 \mathrm{~mL} / \mathrm{min} / 1.73 \mathrm{~m}^{2}$ ) or micro- to macroalbuminuria. Results: After 1 year, eGFR declined by 0.66 and $1.25 \mathrm{~mL} / \mathrm{min} / 1.73 \mathrm{~m}^{2}$ in the intervention and control groups, respectively (mean difference, $0.58 \mathrm{~mL} / \mathrm{min} / 1.73 \mathrm{~m}^{2}$; $95 \% \mathrm{Cl}: 0.15-1.02)$. There were no between-group differenc- es in mean UACR or micro- to macroalbuminuria changes. Moderately/severely impaired eGFR incidence and reversion of moderately to mildly impaired GFR were $40 \%$ lower (HR $0.60 ; 0.44-0.82$ ) and $92 \%$ higher (HR $1.92 ; 1.35-2.73$ ), respectively, in the intervention group. Conclusions: The PREDIMED-Plus lifestyle intervention approach may preserve renal function and delay CKD progression in overweight/ obese adults.

(c) 2021 S. Karger AG, Basel

\section{Introduction}

Chronic kidney disease (CKD) represents a global health burden associated with increased risk of cardiovascular morbidity, premature death, and decreased quality of life [1]. CKD is a heterogeneous condition marked by a decline in estimated glomerular filtration rate (eGFR) and/or albuminuria-characterized kidney damage [2] wherein progression is considerably accelerated when obesity or related cardiovascular risk factors are present [3]. The incidence of CKD is shown to rise in association with the increasing rates of obesity and population aging $[1,2]$. Thus, effective public health strategies to reduce excessive body weight and CKD progression are urgently needed.

Among modifiable lifestyle factors, diet may play a role in the prevention and progression of CKD $[4,5]$. Limited epidemiological evidence suggests that dietary patterns, such as the Mediterranean diet (MedDiet), the Dietary Approaches to Stop Hypertension diet, or the Alternative Healthy Eating Index, are associated with a decreased risk
46

Am J Nephrol 2021;52:45-58 DOI: $10.1159 / 000513664$
Díaz-López et al. 
of, or progression to, CKD [6-10]. However, few randomized clinical trials (RCTs) have evaluated the longterm effect of a dietary intervention on CKD [11-14]. The PREvención con DIetaMEDiterránea (PREDIMED) trial, conducted in older individuals at high cardiovascular risk, showed that both an ad libitum MedDiet and advice to follow a low-fat diet improved eGFR-based renal function after 1 year of intervention [13], without differences in weight changes between groups. In the DIRECT trial, all 3 weight loss energy-reduced diets (energy-reduced MedDiet [erMedDiet], low fat, and low carbohydrate) showed similar benefits on eGFR in overweight/obese participants [11]. The findings of these trials focused specifically on dietary patterns are consistent with a secondary analysis of the only available large-scale RCT, the Look AHEAD, which tested the effectiveness of a lifestyle weight-loss program on kidney function in obese diabetic patients [12]. This trial reported a $31 \%$ decreased risk of CKD in the intensive weight-loss intervention group (low-fat diet plus exercise) compared to the control group [12]. In light of these findings, we hypothesize that weight loss through a multifactorial lifestyle intervention combining an erMedDiet and physical exercise might be an optimal strategy to prevent or delay CKD progression. So far, no large well-conducted RCTs on this matter are available and warrants further research.

Therefore, in the context of the PREDIMED-Plus study, a large lifestyle clinical trial comparing an erMedDiet plus increased physical activity (PA) and behavioral support to an ad libitum MedDiet in participants with metabolic syndrome (MetS) $[15,16]$, we examined the 1 -year effectiveness of this multifaceted intensive lifestyle intervention program on renal function and kidney disease progression.

\section{Methods}

\section{Study Design and Participants}

The analysis was conducted within the framework of the PREDIMED-Plus trial. The design and methods have been previously published $[15,16]$, and the protocol is available at http://predimedplus.com. Briefly, PREDIMED-Plus is an ongoing, 6-year, multicenter, parallel RCT conducted in Spain evaluating the longterm effect of a weight-loss intervention based on an erMedDiet, PA promotion, and behavioral support (intervention), in comparison with usual care recommending an energy-unreduced MedDiet (control), on primary cardiovascular disease (CVD) prevention. Between September 2013 and December 2016, 6,719 participants were recruited in 23 Spanish centers working in 208 primary care clinics of the National Health System. Ethical approval was obtained from the Institutional Review Boards of the 23 participating centers, and all participants signed an informed consent.

Weight-Loss Lifestyle Intervention and

Kidney Function
Eligible participants were men and women aged $55-75$ years, free of CVD at enrollment, with a BMI of $27-40 \mathrm{~kg} / \mathrm{m}^{2}$, and harboring the MetS [17]. Further details of the inclusion/exclusion criteria can be found elsewhere $[15,16]$.

\section{Randomization and Interventions}

Each recruiting center randomly assigned (1:1) candidates to either the intervention or the control. Computer-generated random allocation was centrally elaborated in blocks of 6 participants and stratified by sex, age ( $<65,65-70$, and $>70$ years), and recruiting center. For participant couples sharing the same household, randomization was done by cluster, with the couple as the unit of randomization [15]. The randomization procedure was internet based, and allocation was concealed to all staff members and principal investigators; the assignment was revealed only after the participant was enrolled in the clinical trial. All laboratory staff were masked to treatment, but participants and interventionists were not because the intervention was on lifestyle. Those investigators performing the statistical analyses for this report were also masked to the intervention group.

Participants allocated to the intervention received intensive training to follow an erMedDiet, together with PA promotion and behavioral support aimed to achieve and maintain weight loss [15, 16]. Trained staff delivered 3 visits/month (an individual motivational interview, a telephone call, and a group session) to provide dietary and PA counseling and to achieve weight loss success.

Participants in the control group received nutritional educational sessions every 6 months (an individual visit, a telephone call, and a group session) on an ad libitum MedDiet with the same written dietary material and instructions used in the PREDIMED study [18], along with general lifestyle recommendations for managing MetS. No specific advice for increasing PA or weight loss was provided.

All participants received free extra virgin olive oil ( $1 \mathrm{~L} /$ month) and nuts (125 g/month) to reinforce their adherence to the MedDiet. Details about the interventions are available at the website http://predimedplus.com and somewhere else $[15,16]$.

\section{Measurements}

At baseline and 1 year, participants completed a general medical questionnaire (sociodemographic variables, educational achievement, lifestyle factors, history of illnesses, and medication use), a 17-item questionnaire to assess the degree of adherence to the erMedDiet (modified version of the previously validated 14item questionnaire used in the PREDIMED trial) [19], a 143-item semiquantitative food-frequency questionnaire [20], a validated REGICOR Short Physical Activity Questionnaire [21], and the validated Spanish version of the Nurses' Health Study questionnaire to assess sedentary behaviors [22]. At each visit, weight, height, waist circumference, and blood pressure were measured. At baseline and 1 year, blood samples and spot morning urine were collected after an overnight fast, and routine biochemical analyses including fasting glucose, lipid profile, serum creatinine (SCr), and urinary creatinine and albumin concentrations were performed.

\section{Outcomes}

The primary endpoint of the present study was the 1-year change in kidney function, assessed as changes in SCr-based eGFR from baseline calculated using the CKD-Epi equation [23]. Secondarily, we assessed change from baseline to 1 year in urine albu- 
Table 1. Baseline characteristics of study participants

\begin{tabular}{|c|c|c|c|}
\hline & $\begin{array}{l}\text { All } \\
n=6,719\end{array}$ & $\begin{array}{l}\text { Intervention group } \\
n=3,335\end{array}$ & $\begin{array}{l}\text { Control group } \\
n=3,384\end{array}$ \\
\hline Mean age (SD), yr & $65.0(4.9)$ & $64.9(4.9)$ & $65.0(4.9)$ \\
\hline Male, $n(\%)$ & $3,450(51.3)$ & $1,717(51.5)$ & $1,733(51.2)$ \\
\hline Mean weight (SD), kg & $86.6(13.0)$ & $86.7(13.0)$ & $86.5(12.9)$ \\
\hline Mean BMI (SD), $\mathrm{kg} / \mathrm{m}^{2}$ & $32.6(3.5)$ & $32.6(3.4)$ & $32.6(3.5)$ \\
\hline \multicolumn{4}{|l|}{ Mean waist circumference (SD), cm } \\
\hline Men & $111.0(8.8)$ & $110.9(8.6)$ & $111.1(9.0)$ \\
\hline Women & $104.0(9.2)$ & $104.0(9.4)$ & $104.0(9.1)$ \\
\hline Mean systolic blood pressure (SD), mm Hg & $139.5(16.9)$ & $139.5(17.2)$ & $139.5(16.6)$ \\
\hline Mean diastolic blood pressure (SD), $\mathrm{mm} \mathrm{Hg}$ & $81.0(10.0)$ & $80.9(10.0)$ & $80.8(9.9)$ \\
\hline Current smokers, $n(\%)$ & $846(12.6)$ & $453(13.6)$ & $393(11.6)$ \\
\hline Former smokers, $n(\%)$ & $2,901(43.2)$ & $1,390(41.7)$ & $1,511(44.6)$ \\
\hline Mean PA (SD), MET-min/day & $353.5(329.6)$ & $338.9(315.3)$ & $367.8(342.7)$ \\
\hline Mean erMedDiet (SD), 0-17 items & $8.5(2.7)$ & $8.4(2.6)$ & $8.5(2.7)$ \\
\hline \multicolumn{4}{|l|}{ Medications, $n(\%)$} \\
\hline Lipid-lowering drugs & $3,458(51.5)$ & $1,751(52.5)$ & $1,707(50.4)$ \\
\hline Oral blood glucose-lowering drugs & $1,736(25.8)$ & $884(26.5)$ & $852(25.2)$ \\
\hline Insulin treatment & $1,725(4.5)$ & $135(4.0)$ & $144(4.3)$ \\
\hline Antihypertensive drugs & $5,254(78.2)$ & $2,588(77.6)$ & $2,666(78.8)$ \\
\hline ARBs & $2,429(36.2)$ & $1,201(36.0)$ & $1,228(36.3)$ \\
\hline ACEis & $2,009(29.9)$ & $963(28.9)$ & $1,046(30.9)$ \\
\hline \multicolumn{4}{|l|}{ Education, $n(\%)$} \\
\hline Primary school & $3,293(49.0)$ & $1,594(47.8)$ & $1,699(50.2)$ \\
\hline First-degree high school & $1,936(28.8)$ & $1,013(30.4)$ & $923(27.3)$ \\
\hline High school or university & $1,490(22.2)$ & $728(21.8)$ & $762(22.5)$ \\
\hline Obesity $\left(\mathrm{BMI} \geq 30 \mathrm{~kg} / \mathrm{m}^{2}\right), n(\%)$ & $4,932(73.4)$ & $2,445(73.3)$ & $2,487(73.5)$ \\
\hline Hypertension, $n(\%)$ & $5,767(85.8)$ & $2,865(85.9)$ & $2,902(85.8)$ \\
\hline Type 2 diabetes mellitus, $n(\%)^{\mathrm{a}}$ & $2,046(30.4)$ & $1,022(30.6)$ & $1,024(30.3)$ \\
\hline Family history of premature CHD, $n(\%)$ & $1,126(16.8)$ & $538(16.1)$ & $588(17.4)$ \\
\hline Mean fasting glucose (SD), $\mathrm{mg} / \mathrm{dL}$ & $113.5(29.3)$ & $113.3(28.4)$ & $113.7(30.2)$ \\
\hline Mean LDL cholesterol (SD), mg/dL & $119.2(32.9)$ & $119.4(32.8)$ & $119.2(33.0)$ \\
\hline Mean HDL cholesterol (SD), mg/dL & $48.1(11.8)$ & $48.0(11.9)$ & $48.3(11.8)$ \\
\hline Mean triglycerides (SD), mg/dL & $152.4(77.8)$ & $151.4(77.1)$ & $153.3(78.5)$ \\
\hline
\end{tabular}

Data are mean (SD) or $n(\%)$. BMI, body mass index; PA, physical activity; erMedDiet, energy-restricted Mediterranean diet; ARBs, angiotensin-type 2 receptor blockers; ACEis, angiotensin-converting enzyme inhibitors. ${ }^{a}$ Current diabetes was defined as previous diagnosis of diabetes, glycated hemoglobin (HbA1c) $\geq 6.5 \%$, use of antidiabetic medication, or having fasting glucose $>126 \mathrm{mg} / \mathrm{dL}$ in both the screening visit and baseline visit.

min-to-creatinine ratio (UACR). Urinary creatinine and albumin concentrations were determined in spot morning urine samples, and UACR was calculated $(\mathrm{mg} / \mathrm{g})$. To avoid the influence of extreme outliers of UACR at baseline $(n=15,0.4 \%)$ or at 1 -year assessment $(n=23,0.6 \%)$, we truncated maximum values at 500 $\mathrm{mg} / \mathrm{g}$. Other secondary outcomes included incidence of moderately/severely impaired eGFR $\left(<60 \mathrm{~mL} / \mathrm{min} / 1.73 \mathrm{~m}^{2}\right)$ and microand macroalbuminuria and reversion of moderately (45 to $<60$ $\mathrm{mL} / \mathrm{min} / 1.73 \mathrm{~m}^{2}$ ) to mildly impaired eGFR $(60$ to $<90 \mathrm{~mL} / \mathrm{min} / 1.73$ $\mathrm{m}^{2}$ ) and micro- and macroalbuminuria after 1 year of intervention. Microalbuminuria was defined as UACR between 30 and 300 $\mathrm{mg} / \mathrm{g}$, and macroalbuminuria as UACR $\geq 300 \mathrm{mg} / \mathrm{g}$ regardless of sex. Given the small number of participants with UACR $\geq 300$ $\mathrm{mg} / \mathrm{g}$ at baseline $(n=31[0.8 \%] ; 11$ in the intervention group and
20 in the control group) or at the 1 -year assessment ( $n=45$ [1.2\%]; 19 in the intervention group and 26 in the control group), cutpoints of UACR $\geq 30 \mathrm{mg} / \mathrm{g}$ were used to define micro- and macroalbuminuria. Incident cases of moderately/severely impaired eGFR or micro- and macroalbuminuria were determined when participants who did not meet the criteria for the kidney outcome at baseline met the criteria at 1 year. Conversely, participants who met the criteria for the kidney outcome at baseline but not at 1 year were considered to have reverted from moderately to mildly impaired eGFR or micro- and macroalbuminuria. Both primary and secondary renal outcomes of the current study were explicitly prespecified intermediate outcomes of the PREDIMED-Plus trial, as is detailed in the PREDIMED-Plus Statistical Analysis Plan, which has been previously reported[24].
48 
Statistical Analyses

For the present interim analysis, a sample size of 5,990 participants (intervention, $n=2,956$; control, $n=3,034$ ) assessed at 1 year provided $>80 \%$ power at a $5 \%$ significance level (1-sided) to detect a difference of $0.58 \mathrm{~mL} / \mathrm{min} / 1.73 \mathrm{~m}^{2}$ in the main outcome (1-year change in eGFR) between groups, assuming a common SD (of the difference in mean changes) of $8.5 \mathrm{~mL} / \mathrm{min} / 1.73 \mathrm{~m}^{2}$. Data are shown as mean (SD), number (percentage), or mean (95\% CI) unless otherwise indicated. The analysis for the primary (eGFR) and secondary (UACR) continuous endpoints was conducted on completers only, and a modified intention-to-treat population (mITT) was utilized as a sensitivity analysis, following a multiple imputation method. The mITT analyses included all participants randomly assigned with a baseline measure of eGFR and/or UACR, regardless of whether they had measurements at the 1-year followup visit or not, after exclusion of participants who developed cancer or underwent bariatric surgery. As previously reported [16], all missing data for the eGFR $(n=731,10.8 \%)$ and UACR $(n=1,104$, $22.8 \%$ ) at 1 year were estimated from multiple imputation using an iterative Markov chain Monte Carlo method (STATA "mi" command) that simulates multiple values to impute (fill-in) each missing value. Then, each imputed dataset was analyzed separately and finally resulted were pooled together. We generated $20 \mathrm{im}$ putations for each missing measurement from regression equations to predict these outcomes. The imputation models included as predictors all variables in Table 1, group allocation, and the baseline value of the imputed variable. Analyses of completers included only participants who had both baseline and 1-year measurements, omitting imputed data. For other secondary endpoints, completer analyses were conducted. Continuous outcomes were assessed for normality using both Shapiro-Wilk test and visual inspection (normal plots [histogram] and Q-Q plot [quantile-quantile plot]). Within- and between-group differences in mean changes at 1 year for eGFR and UACR were evaluated by linear regression analyses adjusting for baseline eGFR or UACR values. We analyzed the full cohort and subgroups stratified (considered as a post hoc analysis) according to baseline eGFR $(<60,60$ to $<90$, and $\left.\geq 90 \mathrm{~mL} / \mathrm{min} / 1.73 \mathrm{~m}^{2}\right)$ and UACR $(<30$ and $\geq 30 \mathrm{mg} / \mathrm{g})$ values. Stratified analyses by sex, age, BMI, hypertension, and diabetes were also performed. We used robust variance estimators to account for intracluster correlations, considering as clusters the members of the same household ( $n=395$ couples). The proportion of participants who met the kidney outcome criteria were compared with $\chi^{2}$ tests. Separate Cox proportional hazards models were used to estimate the adjusted hazard ratio (HR, 95\% CIs) of moderately/severely impaired eGFR and micro- and macroalbuminuria incidence and reversion of moderately to mildly impaired eGFR and micro- and macroalbuminuria in the intervention compared with the control. Models were adjusted for sex, age, baseline BMI, diabetes, systolic and diastolic blood pressure, smoking, educational level, PA, erMedDiet score, oral glucose-lowering agents, lipid-lowering drugs, antihypertensive medication use, and baseline eGFR or UACR values. All models were stratified by the recruiting center with robust standard errors to account for intracluster correlations. Person-time of follow-up was calculated as the interval between the randomization date and the date of the 1-year visit.

We also performed separate multivariable linear regression analyses to test associations between eGFR and UACR changes (as continuous variables) and changes in body weight, erMedDiet score, TV-viewing time, and PA as independent variables at 1 year (both, as continuous and categorical variables). For these analyses, participants from both intervention and control groups were pooled. Multivariable models were adjusted for baseline eGFR or UACR values, group allocation, and the abovementioned confounders plus changes in systolic and diastolic blood pressure. Statistical significance was set at $p<0.05$. All analyses were performed using STATA, version 15.0 (StataCorp LP, College Station, TX, USA) using the available March 12, 2019, PREDIMED-Plus database.

\section{Results}

Between September 2013 and December 2016, 6,874 participants were randomly assigned to either the intervention $(n=3,406)$ or the control $(n=3,468)$. For the present study, we excluded participants who developed any type of cancer ( $n=65 ; 36$ in the intervention group and 29 in the control group) or underwent bariatric surgery ( $n=1$ in the intervention group) during the first year or had missing eGFR $(n=89)$ and/or UACR $(n=1,975)$ measurements at baseline. A final sample of 6,719 participants was analyzed. The sample size for the mITT analyses was 6,719 participants for eGFR changes and 4,833 participants for UACR changes. For the completer analyses, 5,990 participants who had eGFR and 3,715 participants who had UACR measurements at baseline and 1 year were included (see online suppl. Fig. 1; see www. karger.com/doi/10.1159/000513664 for all online suppl. material). There were no significant differences in the baseline characteristics between the intervention and control groups in the current analysis (Table 1).

At 1 year, the intervention group achieved greater reductions in adiposity parameters compared with the control group (online suppl. Table 1). Mean 1-year weight loss from baseline was $-3.7 \mathrm{~kg}$ ( $95 \% \mathrm{CI}:-3.8$ to -3.5$)$ in the intervention group and $-0.7 \mathrm{~kg}$ ( $95 \% \mathrm{CI}:-0.9$ to -0.6$)$ in the control group (between-group comparison, $p<$ 0.0001). In terms of compliance with the intervention, beneficial changes in diet, sedentary behaviors, and PA were significantly greater in the intervention versus the control group (between-group comparison, $p<0.0001$ ) (online suppl. Table 1). Except for increased fasting glucose and lipid-lowering medications (more prevalent in the control group), 1-year changes in use of insulin and antihypertensive agents, including angiotensin-converting enzyme inhibitors (ACEis) and angiotensin-type 2 receptor blockers (ARBs), were similar between the 2 groups (online suppl. Table 2). Table 2 shows the 1-year intervention effects on eGFR and UACR for the entire 


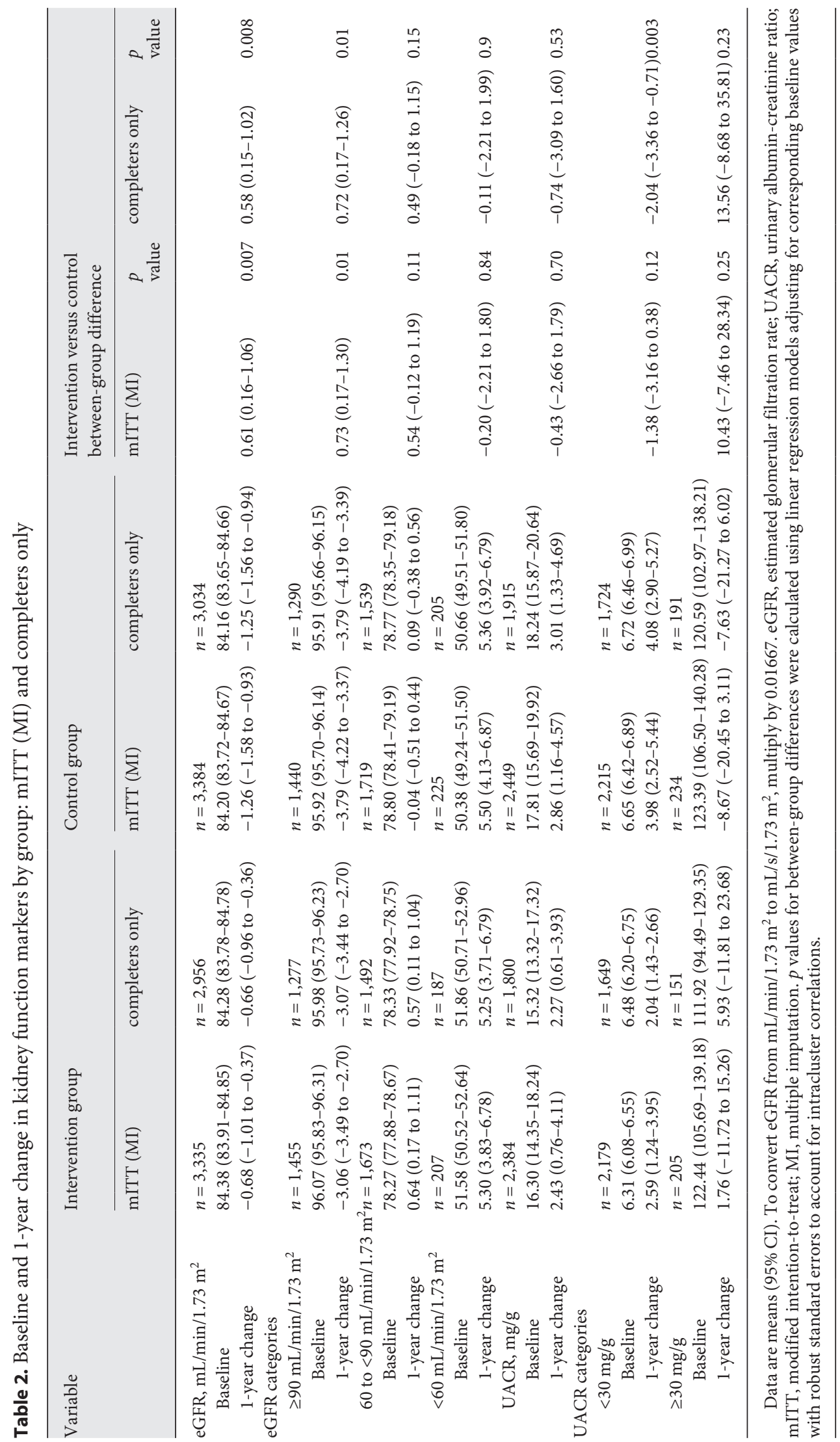


study population and by prespecified subgroups. Completer analysis indicated mean baseline SCr was 74.57 $\mu \mathrm{mol} / \mathrm{L}$ (95\% CI: 73.99-75.19) and $74.26 \mu \mathrm{mol} / \mathrm{L}$ (95\% CI: $73.65-74.86$ ), while eGFR was $84.28 \mathrm{~mL} / \mathrm{min} / 1.73 \mathrm{~m}^{2}$ (95\% CI: $83.78-84.78)$ and $84.16 \mathrm{~mL} / \mathrm{min} / 1.73 \mathrm{~m}^{2}(95 \%$ CI: 83.65-84.66), in the intervention and control groups, respectively. $\mathrm{SCr}$ was unchanged in the intervention group $(0.14 \mu \mathrm{mol} / \mathrm{L}$ [ $95 \% \mathrm{CI}:-0.23$ to $0.50, p=0.51])$ and increased by $0.70 \mu \mathrm{mol} / \mathrm{L}$ (95\%: $0.32-1.09, p<0.001$ ) in the control group after 1 year (between-group comparison, $p=0.03)$. After 1 year, eGFR changed by $-0.66 \mathrm{~mL} /$ $\mathrm{min} / 1.73 \mathrm{~m}^{2}$ (95\% CI: -0.96 to -0.36 ) in the intervention group and by $-1.25 \mathrm{~mL} / \mathrm{min} / 1.73 \mathrm{~m}^{2}$ (95\% CI: -1.56 to -0.94 ) in the control group (delta mean difference, 0.58 $\mathrm{mL} / \mathrm{min} / 1.73 \mathrm{~m}^{2}$ [95\% CI: 0.15-1.02]; $\left.p=0.008\right)$. Mean baseline UACR was $15.32 \mathrm{mg} / \mathrm{g}$ (95\% CI: 13.32-17.32) and $18.24 \mathrm{mg} / \mathrm{g}$ (95\% CI: 15.87-20.64) in the intervention and control groups, respectively. Mean 1-year changes were $2.27 \mathrm{mg} / \mathrm{g}$ (95\% CI: 0.61-3.93) in the intervention group and $3.01 \mathrm{mg} / \mathrm{g}$ (95\% CI: 1.33-4.69) in the control group (between-group comparison, $p=0.53$ ) (Table 2). Analyses were repeated with all values, including extreme outliers for UACR, and results were similar (data not shown).

Overall, analyses stratified by sex, age, BMI, hypertension, and diabetes status revealed similar trends (online suppl. Table 3$)$. The subgroup analyses according to baseline eGFR $\left(<60,60\right.$ to $<90$, and $\left.\geq 90 \mathrm{~mL} / \mathrm{min} / 1.73 \mathrm{~m}^{2}\right)$ and UACR $(<30$ and $\geq 30 \mathrm{mg} / \mathrm{g})$ values are shown in Table 2 . Regarding eGFR changes, significant between-group differences were found among participants with normal eGFR $\left(\geq 90 \mathrm{~mL} / \mathrm{min} / 1.73 \mathrm{~m}^{2}, p=0.01\right)$, with a mean difference of $0.72 \mathrm{~mL} / \mathrm{min} / 1.73 \mathrm{~m}^{2}$ (95\% CI: $\left.0.17-1.26\right)(p=$ 0.01 ). Even though there were no statistically significant between-group differences among participants with an initial mildly impaired eGFR (60 to $<90 \mathrm{~mL} / \mathrm{min} / 1.73$ $\mathrm{m}^{2}$ ), eGFR improved by $0.64 \mathrm{~mL} / \mathrm{min} / 1.73 \mathrm{~m}^{2}$ in the intervention group, while it did not significantly change $\left(-0.04 \mathrm{~mL} / \mathrm{min} / 1.73 \mathrm{~m}^{2}\right)$ in the control group (betweengroup comparison, $p=0.11$ ). Although eGFR levels greatly increased in both groups $\left(\sim 5 \mathrm{~mL} / \mathrm{min} / 1.73 \mathrm{~m}^{2}\right)$ among participants with moderately/severely impaired eGFR $\left(<60 \mathrm{~mL} / \mathrm{min} / 1.73 \mathrm{~m}^{2}\right)$, no differences were found between groups $(p=0.90)$. The analysis revealed a nonsignificant group_intervention*eGFR_category interaction effect ( $p$ for interaction $=0.80$ ). Regarding UACR changes, our data indicated lesser impairment in the intervention group compared to the control group in those participants with normal UACR $(<30 \mathrm{mg} / \mathrm{g})$ (delta mean difference, $-2.04 \mathrm{mg} / \mathrm{g}$ [95\% CI: -3.36 to -0.71$] ; p=0.003)$.
However, change in UACR levels was not different between groups in participants with UACR $>30 \mathrm{mg} / \mathrm{g}$ ( $p=$ $0.23)$. In this case, the group intervention*UACR_category interaction term was statistically significant ( $p$ for interaction $<0.001$ ) (Table 2). The results of the mITT analyses using a multiple imputation method were similar to the main analyses using complete cases (Table 2). Additionally, we also repeated the main analyses (1-year intervention effects on eGFR and UACR) after controlling for the same set of potential confounders used in the multivariable model that adjusted for CKD risk plus 1-year changes in systolic pressure and 1-year changes in fasting glucose levels, but results remained unchanged (data not shown).

One-year moderately/severely impaired eGFR prevalence was $1.9 \%$ lower in the intervention group than in the control group $(p=0.003)$ (Table 3$)$. Compared with the control group, the intervention group showed a higher reversion rate of moderately to mildly impaired eGFR $(10.1 \%, p=0.04$ vs. the control group) and lower incidence rate of moderately/severely impaired eGFR $(-1.1 \%$, $p=0.02$ vs. the control group). The reversion and incidence rates of micro- and macroalbuminuria were not significantly lower in the intervention group compared to the control group (Table 3 ).

The multivariable-adjusted HR of moderately/severely impaired eGFR incidence and reversion of moderately to mildly impaired eGFR in the intervention group was 0.60 (95\% CI: 0.44-0.82, $p=0.001)$ and 1.92 (95\% CI: $1.35-2.73, p<0.001)$, respectively, compared to the control group (Fig. 1). Results were similar when the data were analyzed using a composite definition to ascertain the moderately/severely impaired eGFR incidence and reversion of moderately to mildly impaired eGFR (i.e., both outcomes accompanied by at least an additional $10 \%$ change in eGFR from baseline) in order to minimize the possibility of including individuals with baseline eGFR values very close to $60 \mathrm{~mL} / \mathrm{min} / 1.73 \mathrm{~m}^{2}$. This was done to mitigate subsequent changes in the eGFR category due to random variation of estimated eGFR (data not shown). No between-group differences in the incidence or reversion of micro- and macroalbuminuria were observed (Fig. 1).

Multivariable linear regression analyses in the full cohort showed that weight loss $(p<0.001)$ and improved erMedDiet $(p=0.002)$ were each independently associated with increased eGFR at 1 year after controlling for confounders. When changes in weight and other lifestyle variables (erMedDiet score, TV-viewing time, and PA) 
Table 3. Kidney outcomes by group assignment: completers only

\begin{tabular}{|c|c|c|c|c|}
\hline \multirow[t]{2}{*}{ Criteria } & \multicolumn{2}{|c|}{$\begin{array}{l}\text { Group assignment, participants, } \\
n(\%)\end{array}$} & \multicolumn{2}{|c|}{ Intervention versus control } \\
\hline & $\begin{array}{l}\text { intervention } \\
\text { group }\end{array}$ & control group & $\begin{array}{l}\text { between-group } \\
\text { difference }^{\ddagger}\end{array}$ & $p$ value \\
\hline $\begin{array}{l}N \\
\mathrm{eGFR}<60 \mathrm{~mL} / \mathrm{min} / 1.73 \mathrm{~m}^{2}, n(\%)\end{array}$ & $n=2,956$ & $n=3,034$ & & \\
\hline $\begin{array}{l}\text { Baseline prevalence } \\
1-y r \text { prevalence } \\
\text { Reversion rate }^{\mathrm{a}} \\
\text { Incidence rate }^{\mathrm{b}}\end{array}$ & $\begin{aligned} & 187(6.3) \\
& 180(6.1) \\
& 80(42.8) \\
& 73(2.6)\end{aligned}$ & $\begin{aligned} 205 & (6.7) \\
244 & (8.0) \\
67 & (32.7) \\
106 & (3.7)\end{aligned}$ & $\begin{array}{l}-0.4(-1.68 \text { to } 0.82) \\
-1.9(-3.25 \text { to }-0.65) \\
10.1(0.50-19.69) \\
-1.1(-2.03 \text { to }-0.19)\end{array}$ & $\begin{array}{l}0.50 \\
0.003 \\
0.04 \\
0.02\end{array}$ \\
\hline $\begin{array}{l}N \\
\mathrm{UACR} \geq 30 \mathrm{mg} / \mathrm{g}, n(\%)\end{array}$ & $n=1,800$ & $n=1,915$ & & \\
\hline $\begin{array}{l}\text { Baseline prevalence } \\
1-y r \text { prevalence } \\
\text { Reversion rate }^{\mathrm{a}} \\
\text { Incidence rate }\end{array}$ & $\begin{aligned} 151 & (8.4) \\
183 & (10.2) \\
40 & (26.5) \\
72 & (4.4)\end{aligned}$ & $\begin{array}{c}191(10.0) \\
229(12.0) \\
60(31.4) \\
98(5.7)\end{array}$ & $\begin{array}{l}-1.6(-3.44 \text { to } 0.27) \\
-1.8(-3.81 \text { to } 0.22) \\
-4.9(-14.68 \text { to } 4.83) \\
-1.3(-2.79 \text { to } 0.16)\end{array}$ & $\begin{array}{l}0.09 \\
0.08 \\
0.32 \\
0.08\end{array}$ \\
\hline
\end{tabular}

Data are $n(\%)$. eGFR, estimated glomerular filtration rate; UACR, urinary albumin-creatinine ratio. $p$ values for between-group differences were calculated using linear regression models. ${ }^{\ddagger}$ Data are percentage (95\% CI). $p$ values for differences between groups by $\chi^{2}$ tests. ${ }^{\text {a }}$ Reversion rate indicates the $n(\%)$ of participants who met the criterion for the kidney outcome at baseline (eGFR $<60 \mathrm{~mL} / \mathrm{min} / 1.73 \mathrm{~m}^{2}$ [moderately/severely impaired eGFR] or UACR $\geq 30 \mathrm{mg} / \mathrm{g}$ ) but not at the 1 -year assessment (eGFR between 60 and $<90 \mathrm{~mL} / \mathrm{min} / 1.73 \mathrm{~m}^{2}$ [mildly impaired eGFR] or UACR $<30 \mathrm{mg} / \mathrm{g}$ ). ${ }^{\mathrm{b}}$ Incidence rate indicates the $n(\%)$ of participants who did not meet the criterion for the kidney outcome at baseline (eGFR $\geq 60 \mathrm{~mL} / \mathrm{min} / 1.73 \mathrm{~m}^{2}$ [mildly impaired GFR] or normal eGFR $\left[\geq 90 \mathrm{~mL} / \mathrm{min} / 1.73 \mathrm{~m}^{2}\right]$ or UACR $\left.<30 \mathrm{mg} / \mathrm{g}\right)$ but met the criterion at the 1 -year assessment $(\mathrm{eGFR}<60 \mathrm{~mL} /$ $\mathrm{min} / 1.73 \mathrm{~m}^{2}$ or UACR $\geq 30 \mathrm{mg} / \mathrm{g}$ ).

were accounted for as predictors in the same model, these associations remained significant $(p \leq 0.03)$ (Table 4$)$.

Greater increases in eGFR were observed when participants in the lowest weight loss categories were compared to those in the highest categories ( $5-10 \%$ and $\geq 10 \%$ loss) ( $p$ for trend $=0.004$ ) and for those with an erMedDiet adherence score ( $\geq 7$ point increase) ( $p$ for trend $=$ 0.01 ) (online suppl. Table 4). Considering UACR as the outcome, only weight loss $(p<0.001)$ and reduction in TV-viewing time $(p=0.01)$ were independently associated with decreased UACR. The associations were similar when all predictor variables were entered into the same model ( $p \leq 0.02$ ) (Table 4$)$. Compared to participants who gained weight or remained weight stable $(<1 \%$ weight loss), those who lost $1-5,5-10$, and $>10 \%$ body weight showed a graded decrease in UACR levels ( $p$ for trend $=$ 0.006). An opposite pattern of association with AUCR was observed with greater increases in TV-viewing time ( $p$ for trend $=0.49$ ) (online suppl. Table 4 ). There were no significant interactions between intervention assignment and these variables with eGFR or UACR (online suppl. Fig. 2).

\section{Discussion}

The novel results of our RCT indicate an intensive lifestyle intervention aimed at weight loss based on an erMedDiet and increased PA may preserve renal function and delay CKD progression in overweight/obese adults with MetS. Weight loss and high erMedDiet adherence were both independently associated with improvements in kidney function.

In our study, eGFR declined in both groups at 1 year but, compared to the control group, the eGFR decline rate was about $0.6 \mathrm{~mL} / \mathrm{min} / 1.73 \mathrm{~m}^{2}$ lower in the intervention group, which experienced a mean weight loss of just $4.2 \%$. These favorable effects on eGFR were similar by sex, age, BMI, hypertension, and diabetes status. Of note, 86 and $78 \%$ of participants had hypertension and used antihypertensive agents, respectively, making it difficult to assess the role of hypertension on renal function.

In healthy individuals, an eGFR decline of about $1 \mathrm{~mL} /$ $\mathrm{min} / 1.73 \mathrm{~m}^{2} /$ year generally reflects the natural aging process [2]. Accordingly, the observed mean rate of eGFR decline of uncertain clinical relevance in the intervention 


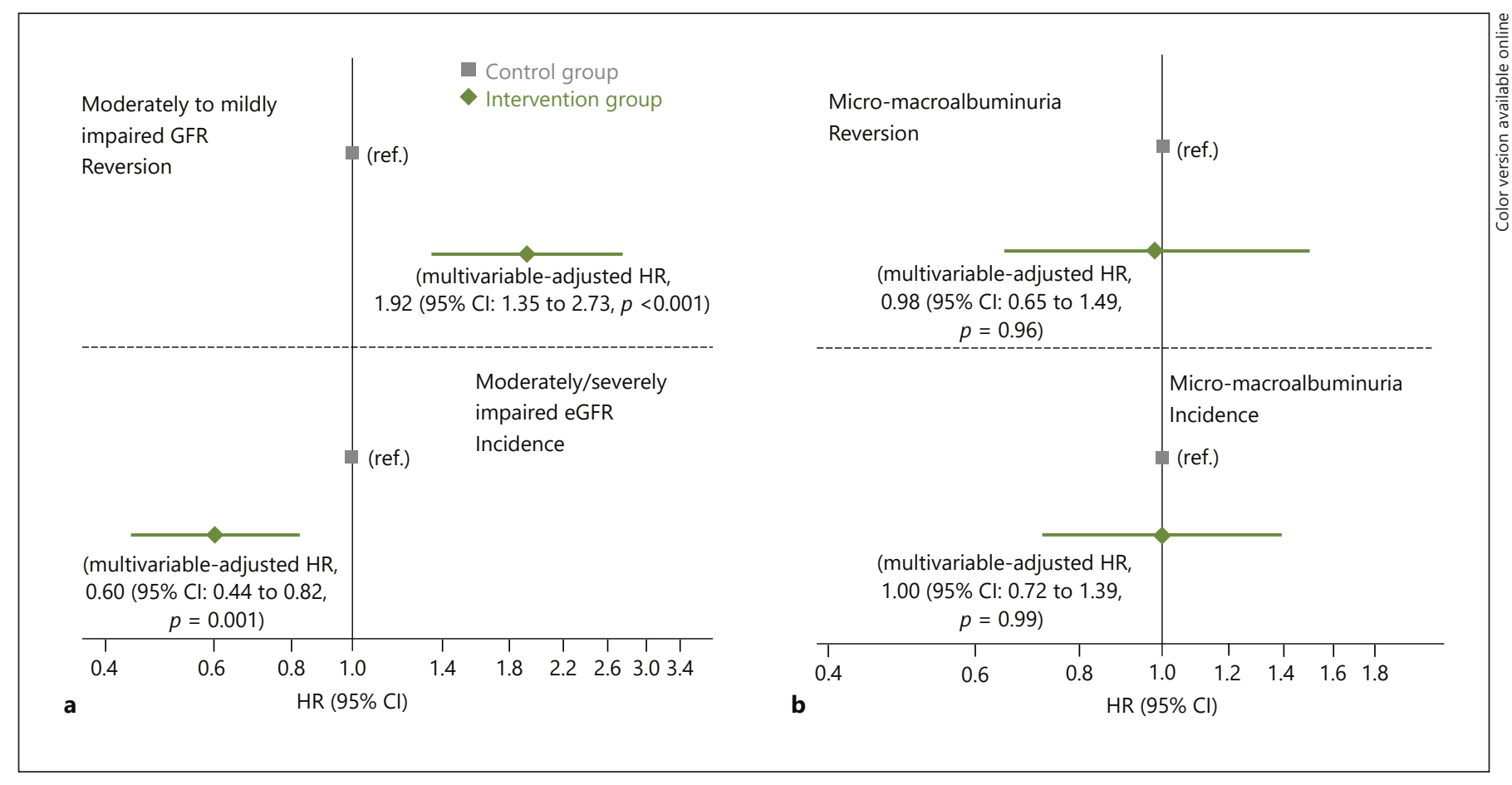

Fig. 1. a HR $(95 \% \mathrm{CI})$ of 1 -year reversion to mildly impaired eGFR $\left(60\right.$ to $<90 \mathrm{~mL} / \mathrm{min} / 1.73 \mathrm{~m}^{2}$ ) among participants who had moderately/severely impaired eGFR $\left(<60 \mathrm{~mL} / \mathrm{min} / 1.73 \mathrm{~m}^{2}\right)$ at baseline (top) and incidence of CKD among participants who did not have moderately/severely impaired eGFR $\left(\geq 60 \mathrm{~mL} / \mathrm{min} / 1.73 \mathrm{~m}^{2}\right)$ at baseline (bottom) in the intervention group compared with the control group. b HR (95\% CI) of 1-year reversion of micro- and macroalbuminuria among participants who had micro- and macroalbuminuria (UACR $\geq 30 \mathrm{mg} / \mathrm{g}$ ) at baseline (top) and incidence of micro- and macroalbuminuria among participants who did not have micro- and macroalbuminuria (UACR $<30 \mathrm{mg} / \mathrm{g}$ ) at baseline (bottom) in the intervention group compared with the control group. The Cox proportional hazards models were adjusted for sex

group was $<1 \mathrm{~mL} / \mathrm{min} / 1.73 \mathrm{~m}^{2}$ at 1 year. It should be noted that our population comprises older individuals with overweight/obesity and MetS, which are well-known risk factors for accelerated eGFR decline over and above that imposed by natural aging $[2,3]$. Our findings reinforce the importance of weight loss through a healthy lifestyle on preserving renal function, particularly among this vulnerable population group.

We also found that the intervention effect on eGFR changes was closely related to initial eGFR in magnitude and direction. The presence of obesity-related comorbidities alongside aging could partly explain the highest eGFR decline found in subjects with an initial eGFR $\geq 90$ $\mathrm{mL} / \mathrm{min} / 1.73 \mathrm{~m}^{2}$. Another explanation could be that small changes in $\mathrm{SCr}$ above or below the normal range (men/women), age (continuous), baseline BMI (continuous), diabetes (yes/no), systolic and diastolic blood pressure (continuous), smoking (never, current, or former smoker), educational level (primary/secondary education or academic/graduate), PA in MET-min/day (continuous), erMedDiet score (0-17), oral glucose-lowering agents (yes/no), lipid-lowering drugs (yes/no), antihypertensive use (yes/no), and for corresponding baseline eGFR or UACR values. All models were stratified by the recruitment center. Robust standard errors to account for intracluster correlations were used. HR, hazard ratio; eGFR, estimated glomerular filtration rate; UACR, urine albumin-to-creatinine ratio; PA, physical activity. could have a relatively higher influence on eGFR fluctuations [25]. In our study, eGFR increased significantly by $0.57 \mathrm{~mL} / \mathrm{min} / 1.73 \mathrm{~m}^{2}$ only in the intervention group participants with an initial eGFR of 60 to $\leq 90 \mathrm{~mL} / \mathrm{min} / 1.73$ $\mathrm{m}^{2}$. This suggests that the treatment benefits observed on eGFR were more pronounced in participants with modestly impaired renal function at baseline, which emphasizes the importance of early lifestyle interventions in populations at risk.

We also found that at 1 year, UACR increased less in normoalbuminuric participants in the intervention group, although no benefit was observed among those with established micro- or macroalbuminuria. Possibly a greater and sustained weight loss over a longer period of time is necessary to reduce UACR in obese participants 
Table 4. Associations of 1-year changes in weight, MedDiet, TV-viewing, and PA with kidney function markers changes: completers only

\begin{tabular}{|c|c|c|c|c|c|c|c|c|}
\hline Models & $N$ & $\begin{array}{l}\Delta \text { in eGFR, } \mathrm{mL} / \mathrm{min} / 1.73 \mathrm{~m}^{2} \\
\text { coefficients } \beta(95 \% \mathrm{CI})\end{array}$ & $p$ value & $R^{2}$ & $N$ & $\begin{array}{l}\Delta \text { in UACR, mg/g } \\
\text { coefficients } \beta(95 \% \mathrm{CI})\end{array}$ & $p$ value & $R^{2}$ \\
\hline Model $1^{\mathrm{a}}$ & 5,872 & & & 0.13 & 3,647 & & & 0.04 \\
\hline Model $1^{\mathrm{a}}$ & 5,872 & & & 0.13 & 3,647 & & & 0.04 \\
\hline$\Delta$ in weight, $\%$ & & $-0.09(-0.14$ to -0.04$)$ & $<0.001$ & & & $0.55(0.27-0.83)$ & $<0.001$ & \\
\hline Model $2^{\mathrm{a}}$ & 5,812 & & & 0.13 & 3,613 & & & 0.04 \\
\hline$\Delta$ in TV-viewing time, $\mathrm{h} / \mathrm{d}$ & & $-0.04(-0.19$ to 0.11$)$ & 0.63 & & & $1.17(0.25-2.10)$ & 0.01 & \\
\hline Model $4^{\mathrm{a}}$ & 5,832 & & & 0.13 & 3,625 & & & 0.03 \\
\hline$\Delta$ in total leisure-time PA, MET-min/d & & $0.00(-0.00$ to 0.001$)$ & 0.09 & & & $-0.00(-0.004$ to 0.003$)$ & 0.9 & \\
\hline Model $5^{\mathrm{a}}$ & 5,766 & & & 0.13 & 3,587 & & & 0.04 \\
\hline$\Delta$ in weight, $\mathrm{kg}$ & & $-0.09(-0.15$ to -0.03$)$ & 0.002 & & & $0.67(0.31-1.02)$ & $<0.001$ & \\
\hline
\end{tabular}

Data are regression coefficients $\beta$ (95\% CI) from multivariate linear regression. MedDiet, Mediterranean diet; PA, physical activity; eGFR, estimated glomerular filtration rate; UACR, urinary albumin-creatinine ratio. ${ }^{a}$ Each model was analyzed independently and adjusted for baseline eGFR or baseline UACR, for the treatment group (intervention/control group), sex (men/women), age ( $<65 / \geq 65$ years), baseline BMI (continuous), diabetes (yes/no), systolic and diastolic blood pressure (continuous), smoking (never, current, or former smoker), educational level (primary/secondary education or academic/ graduate), lipid-lowering drugs (yes/no), antihypertensive use (yes/no), center (categorized into quartiles by number of participants), and changes in systolic and diastolic blood pressure. Robust standard errors to account for intracluster correlations were used.

with UACR $\geq 30 \mathrm{mg} / \mathrm{g}$. These findings are interesting from a public health perspective, since a minimal increase in the UACR within the normal range has been associated with increased CVD in high-risk individuals [26]. Despite differences in the populations studied and methodology and dietary approaches used, our results are in line with the Look AHEAD findings [12], which showed a protective effect of an intensive weight loss lifestyle intervention with a low-fat diet on CKD progression in diabetic participants. Furthermore, our trial provides new data suggesting that weight loss together with lifestyle changes including a MedDiet intervention may reverse early renal dysfunction progression from moderately to mildly impaired eGFR. However, the results also show that the lifestyle intervention had no beneficial effects on the incidence or reversion of micro- and macroalbuminuria. Further RCTs with longer follow-up and a re-evaluation of the PREDIMED-Plus cohort after longer followup time are needed to confirm these findings.

It is likely that the modest but statistically significant renal-protective effect observed in our study results from a synergistic action from improvement in lifestyle and adiposity parameters. In line with previous findings [27], we showed that weight loss was independently associated with improved eGFR-based kidney function. This supports a direct effect of obesity as a kidney risk factor in older individuals with metabolic disturbances. It has been suggested that renin-angiotensin system activation and resultant oxidant stress and inflammation may partly explain obesity-linked kidney dysfunction [28], which supports the weight loss-related benefit observed in our study. We surmise that such a beneficial effect on eGFRbased renal function is likely to be indirectly mediated by the weight loss-induced improvement in cardiometabolic risk factors - insulin resistance, HbAlc, triglycerides, and HDL cholesterol - achieved by the intervention group after 1-year follow-up [24, 29]. Furthermore, our study is in line with previous reports $[11,13]$ suggesting that increased adherence to the erMedDiet may slow the progression of kidney dysfunction, as previously reported in older individuals at high cardiovascular risk [13]. This may be partially explained by the antioxidant and antiinflammatory effects of this healthy dietary pattern and its individual components on several cardiometabolic risk markers [30-32]. Additionally, in prior PREDIMED reports, we showed that an ad libitum MedDiet protects against kidney dysfunction-related comorbidities, such as hypertension [33], diabetes [34], and MetS [35]. In our 
study, increased TV-viewing time was also independently associated with UACR worsening, confirming the negative impact of sedentary behaviors on metabolism and kidney function [36-38]. Nonetheless, PA was unrelated to changes in kidney function. Despite using validated questionnaires [21], the use of self-reported PA instead of more objective measures could partially explain this finding. At any rate, observational studies in this field have shown mixed results $[38,39]$. Of note, our interventions had minimal impact on medication changes, including antihypertensive agents such as ARBs and ACEis, both considered renoprotective because of their blood pressure-lowering and antiproteinuric effects [40, 41]. This could partly explain the lack of a significant effect on UACR observed in our study.

Besides the short follow-up, our study has other limitations. First, our population consisted of overweight/ obese older Mediterranean individuals with MetS, which prevents generalization of the findings to other populations. Second, kidney function markers were determined only once at baseline and 1 year (at short term), and their known biological variability may have led to some degree of misclassification. We also did not directly measure eGFR using an optimal marker, such as inulin, iothalamate, or iohexol, or 24-h urinary creatinine clearance, as these procedures are costly and time consuming and are not suited to the routine detection of kidney disease. Also, spot morning urine samples were used for the estimation of the albumin excretion rate (expressed as UACR), whereas a 24-h urine collection is considered the gold standard for the determination of albuminuria. Third, although the analyses were adjusted by several confounders that can affect SCr concentrations, we cannot exclude the possibility of residual confounding. We acknowledge that a large weight loss may reduce the muscle mass and SCr causing an increase in eGFR. Surprisingly, we found that $\mathrm{SCr}$ was unchanged in the intervention group experiencing a relatively modest weight loss $(-3.7 \mathrm{~kg})$ and increased by $0.70 \mu \mathrm{mol} / \mathrm{L}$ in the control group after 1 year. Besides, $<5 \%$ weight loss over 1 year yielded no significant decreases in SCr (online suppl. Table 4). By applying methods for determination of body composition, we previously demonstrated that the achieved weight loss was due to a reduction of body fat. Thus, we hypothesize that the $\mathrm{SCr}$ change observed in the intervention group is unlikely to be influenced by the modest weight loss-induced muscle mass reduction. In fact, a recent pooled analysis of 7 RCTs concluded that in patients experiencing a weight reduction of $\sim 2 \mathrm{~kg}$, the creatinine-based CKD-EPI equation was unaffected and could be applied [42]. This issue re- quires further study and confirmation. Lastly, only a small number of subjects had eGFR $<30 \mathrm{~mL} / \mathrm{min} / 1.73 \mathrm{~m}^{2}$ $(n=12)$ and/or UACR $\geq 300 \mathrm{mg} / \mathrm{g}(n=31)$, which limits the ability to assess the interventions impact on eGFR and UACR in advanced renal dysfunction stages.

\section{Conclusions}

The PREDIMED-Plus lifestyle intervention approach may preserve renal function and delay CKD progression in overweight/obese adults with MetS. We hypothesize that long-term renoprotective effects in response to the lifestyle intervention, if sustained over time, may eventually lead to a decreased incidence of kidney failure, CVD events, and mortality in the future.

\section{Acknowledgements}

We thank all the volunteers for the participation and personnel for the contribution in the PREDIMED-Plus trial. We also thank all the investigators of the PREDIMED-Plus study (online suppl. material). CIBEROBN (Centros de Investigación Biomédica en Red: Obesidad y Nutrición), CIBERESP (Centros de Investigación Biomédica en Red: Epidemiología y Salud Pública), and CIBERDEM (Centros de Investigación Biomédica en Red: Diabetes y Enfermedades Metabólicas asociadas) are initiatives of ISCIII, Madrid, Spain. We also thank the PREDIMED-Plus Biobank Network as a part of the National Biobank Platform of the ISCIII for storing and managing the PREDIMED-Plus biological samples. Food companies Hojiblanca (Lucena, Spain) and Patrimonio Comunal Olivarero (Madrid, Spain) donated extra virgin olive oil, and the Almond Board of California (Modesto, CA), American Pistachio Growers (Fresno, CA), and Paramount Farms (Wonderful Company, LLC, Los Angeles, CA) donated nuts. Jordi Salas-Salvadó gratefully acknowledges the financial support by ICREA under the ICREA Academia program.

\section{Statement of Ethics}

The study protocol and procedures were approved according to the ethical standards of the Declaration of Helsinki by the Institutional Review Boards (IRBs) of all the participating institutions: CEI Provincial de Málaga, CEI de los Hospitales Universitarios Virgen Macarena y Virgen del Rocío, CEI de la Universidad de Navarra, CEI de las Illes Balears, CEIC del Hospital Clínic de Barcelona, CEIC del Parc de Salut Mar, CEIC del Hospital Universitari Sant Joan de Reus, CEI del Hospital Universitario San Cecilio, CEIC de la Fundación Jiménez Díaz, CEIC Euskadi, CEI en Humanos de la Universidad de Valencia, CEIC del Hospital Universitario de Gran Canaria Doctor Negrín, CEIC del Hospital Universitario de Bellvitge, CEIC de IMDEA Alimentación, CEIC del Hospital Clínico San Carlos, CEI Provincial de Málaga, CCEIBA de la Investigación Biomédica de Andalucía, CEIC del Hospital Gen- 
eral Universitario de Elche, Comité de Ética del Hospital Universitario Reina Sofía, and CEIC de León. All participants provided informed written consent.

\section{Conflict of Interest Statement}

Dr. Salas-Salvado reported receiving research support from the Instituto de Salud Carlos III (ISCIII), Ministerio de Educación y Ciencia, Departament de Salut Pública de la Generalitat de Catalunya, the European Commission, the California Walnut Commission, Patrimonio Comunal Olivarero, La Morella Nuts, and Borges S.A; receiving consulting fees or travel expenses from Danone, California Walnut Commission, Eroski Foundation, Instituto Danone, Nestle, Nuts for Life, and Abbott Laboratories; receiving nonfinancial support from Hojiblanca, Patrimonio Comunal Olivarero, and Almond Board of California; and serving on the board of and receiving grant support through his institution from the International Nut and Dried Foundation and the Eroski Foundation and grants and personal fees from Instituto Danone. No other disclosures were reported. Dr. Ros reported receiving grants, personal fees, and nonfinancial support from the CaliforniaWalnut Commission during the conduct of the study; grants, personal fees, and nonfinancial support from Alexion; grants from Amgen and Pfizer; grants and personal fees from Sanofi Aventis; personal fees and nonfinancial support from Ferrer International, Danone, and Merck Sharp \& Dohme; and personal fees from Amarin outside the submitted work. Dr. Corella reported receiving grants from ISCIII during the conduct of the study. Dr. Fitó reported receiving grants from ISCIII during the conduct of the study. Dr. Romaguera reported receiving grants from ISCIII during the conduct of the study and grants from Fundación AstraZeneca outside the submitted work. Dr. Vioque reported receiving grants from ISCIII during the conduct of the study. Dr. Alonso-Gómez reported receiving grants from ISCIII during the conduct of the study. Dr. Wärnberg reported receiving grants from ISCIII during the conduct of the study. Dr. Martínez reported receiving grants from ISCIII during the conduct of the study. Dr. Serra-Majem reported receiving grants from ISCIII during the conduct of the study. Dr. Estruch reported receiving grants from Instituto de Salud Carlos III and olive oil for the trial from Fundacion Patrimonio Comunal Olivarerolduring the conduct of the study and personal fees from Brewers of Europe, Fundación Cerveza y Salud, Interprofesional del Aceite de Oliva, Instituto Cervantes, Pernaud Richar, Fundación Dieta Mediterránea, and Wine and Culinary International Forum; nonfinancial support from Sociedad Española de $\mathrm{Nu}$ trición and Fundación Bosch y Gimpera; and grants from Uriach Laboratories outside the submitted work. Dr. Tinahones reported receiving grants from ISCIII during the conduct of the study. Dr. Lapetra reported receiving grants from ISCIII during the conduct of the study. Dr. Pintó reported receiving grants from ISCIII during the conduct of the study; receiving consulting fees from Sanofi Aventis, Amgen, and Abbott laboratories; and receiving lecture personal fees from Esteve, Lacer, and Rubio laboratories. Dr. Tur reported receiving grants from ISCIII during the conduct of the study. Dr. López-Miranda reported receiving grants from ISCIII during the conduct of the study. Dr. Delgado-Rodríguez reported receiving grants from ISCIII during the conduct of the study; grants from the Diputación Provincial de Jaén and the Caja Rural de Jaén. Dr. Matía-Martín reported receiving grants from ISCIII during the conduct of the study; personal fees from Organización Interprofesional Láctea outside the submitted work. Dr. Damiel Martín reported receiving grants from Fundación Cerveza y Salud. Dr. Vidal reported receiving grants from ISCIII during the conduct of the study. Dr. Martínez-González reported receiving grants from ISCIII during the conduct of the study. All other authors declare no competing interests.

\section{Funding Sources}

This work was supported by the official Spanish Institutions for funding scientific biomedical research, CIBER Fisiopatología de la Obesidad y Nutrición (CIBEROBN) and Instituto de Salud Carlos III (ISCIII), through the Fondo de Investigación para la Salud (FIS), which is cofunded by the European Regional Development Fund (5 coordinated FIS projects leaded by J.S.-S and J.V., including the following projects: PI13/00673, PI13/00492, PI13/00272, PI13/01123, PI13/00462, PI13/00233, PI13/02184, PI13/00728, PI13/01090, PI13/01056, PI14/01722, PI14/00636, PI14/00618, PI14/00696, PI14/01206, PI14/01919, PI14/00853, PI14/01374, PI14/00972, PI14/00728, PI14/01471, PI16/00473, PI16/00662, PI16/01873, PI16/01094, PI16/00501, PI16/00533, PI16/00381, PI16/00366, PI16/01522, PI16/01120, PI17/00764, PI17/01183, PI17/00855, PI17/01347, PI17/00525, PI17/01827, PI17/00532, PI17/00215, PI17/01441, PI17/00508, PI17/01732, PI17/00926; PI19/00957, PI19/00386, PI19/00309, PI19/01032, PI19/00576, PI19/00017, PI19/01226, PI19/00781, PI19/01560, and PI19/01332); the Especial Action Project entitled Implementación y evaluación de una intervención intensiva sobre la actividad física Cohorte PREDIMED-Plus grant to J.S.-S.; the European Research Council (Advanced Research Grant 2014-2019; agreement \#340918) granted to M.Á.M.-G.; the Recercaixa (No. 2013ACUP00194) grant to J.S.-S.; grants from the Consejería de Salud de la Junta de Andalucía (PI0458/2013, PS0358/2016, and PI0137/2018); the PROMETEO/2017/017 grant from the Generalitat Valenciana; the SEMERGEN grant; funds from the European Regional Development Fund (CB06/03); International Nut \& Dried Fruit Council - FESNAD (Long-term effects of an energyrestricted Mediterranean diet on mortality and cardiovascular disease 2014-2015, No. 201302) (PI: M.Á.M.-G.); the AstraZeneca Young Investigators Award in Category of Obesity and T2D 2017 (PI: D.R.); grant of support to research groups No. 35/2011 (Balearic Islands Gov.; FEDER funds) (J.A.T. and C.B.); the JR17/00022 (ISCIII) grant to O.C.; the Boosting young talent call grant program for the development of IISPV research projects 2019-2021 (Ref.: 2019/IISPV/03 grant to A.D.-L.); the Societat Catalana d'Endocrinologia i Nutrició (SCEN) Clinical-Research Grant 2019 (IPs: J.S.-S. and A.D.-L.). Collaborative Nutrition and/or Obesity Project for Young Researchers 2019 supported by CIBEROBN entitled Lifestyle Interventions and Chronic Kidney Disease: Inflammation, Oxidative Stress and Metabolomic Profile (LIKIDI study) grant to A.D.-L. None of the funding sources took part in the design, collection, analysis, interpretation of the data, or writing the report, or in the decision to submit the manuscript for publication. 


\section{Author Contributions}

D.C., Mo.F., D.R., J.V., A.M.A.-G., J.W., J.A.M., L.S.-M., R.E., F.J.T., J.L., X.P., J.A.T., J.L.M., M.D.-R., P.M., L.D., J.V., C.V., E.R., M.A.M.-G., and J.S.-S. designed the research. A.D.-L., N.B.-T., V.R., E.T., N.B., D.C., Mo.F., D.R., J.V., A.M.A.-G., J.W., J.A.M., L.S.-M., R.E., F.J.T., J.L., X.P., J.A.T., J.L.M., N.C.I., M.D.-R., P.M., L.D., J.A.P., J.V., C.V., E.R., M.R.-C., J.V.S., A.G., M.F., M.G.H., L.T.S., N.P.-F., M.A.Z., A.S.-V., E.S., J.C.F.-G., J.M.S.-L., M.G.G., M.M.B., J.D.-E., C.O.-A., O.C., M.M., L.T.-C., C.S.S., M.A.M., M.A.M.-G., and J.S.-S. conducted the research. A.D.-L. and J.S.-S. analyzed the data. A.D.-L. and J.S.-S. wrote the article. All authors revised the manuscript for important intellectual content and read and approved the final manuscript. The corresponding author attests that all listed authors meet authorship criteria and that no others meeting the criteria have been omitted. A.D.-L. and J.S.-S. are the guarantors of this work and, as such, had full access to all the data in the study and take responsibility for the integrity of the data and the accuracy of the data analysis.

\section{Availability of Data and Material}

The dataset (including data dictionaries) of PREDIMED-Plus is available to external investigators in order to make possible the replication of the main analyses used for the published article. However, due to the restrictions imposed by the informed consent and the Institutional Review Boards (IRB), bona fide investigators interested in analyzing the PREDIMED-Plus dataset may submit a brief proposal and statistical analysis plan to the corresponding author (J.S.-S.) at jordi.salas@urv.cat. Upon approval from the Steering Committee and IRBs, the data will be made available to them using an onsite secure access data enclave. The study protocol is available at http://predimedplus.com/.

\section{References}

1 Xie Y, Bowe B, Mokdad AH, Xian H, Yan Y, $\mathrm{Li} \mathrm{T}$, et al. Analysis of the Global Burden of Disease study highlights the global, regional, and national trends of chronic kidney disease epidemiology from 1990 to 2016. Kidney Int. 2018;94(3):567-81.

2 Mallappallil M, Friedman EA, Delano BG, McFarlane SI, Salifu MO. Chronic kidney disease in the elderly: evaluation and management. Clin Pract. 2014;11(5):525-35.

3 Gansevoort RT, Correa-Rotter R, Hemmelgarn BR, Jafar TH, Heerspink HJ, Mann JF, et al. Chronic kidney disease and cardiovascular risk: epidemiology, mechanisms, and prevention. Lancet. 2013;382(9889):339-52.

4 Campbell KL, Carrero JJ. Diet for the management of patients with chronic kidney disease; it is not the quantity, but the quality that matters. J Ren Nutr. 2016;26(5):279-81.

5 Goraya N, Wesson DE. Dietary interventions to improve outcomes in chronic kidney disease. Curr Opin Nephrol Hypertens. 2015; 24(6):505-10.

6 Dunkler D, Dehghan M, Teo KK, Heinze G, Gao P, Kohl M, et al. Diet and kidney disease in high-risk individuals with type 2 diabetes mellitus. JAMA Intern Med. 2013;173(18): 1682-92.

7 Dunkler D, Kohl M, Teo KK, Heinze G, Dehghan M, Clase CM, et al. Dietary risk factors for incidence or progression of chronic kidney disease in individuals with type 2 diabetes in the European Union. Nephrol Dial Transplant. 2015;30(Suppl 4):iv76-85.

8 Huang X, Jiménez-Moleón JJ, Lindholm B, Cederholm T, Arnlöv J, Risérus U, et al. Mediterranean diet, kidney function, and mortality in men with CKD. Clin J Am Soc Nephrol. 2013;8(9):1548-55.
9 Khatri M, Moon YP, Scarmeas N, Gu Y, Gardener $\mathrm{H}$, Cheung $\mathrm{K}$, et al. The association between a Mediterranean-style diet and kidney function in the Northern Manhattan Study cohort. Clin J Am Soc Nephrol. 2014;9(11): 1868-75.

10 Rebholz CM, Crews DC, Grams ME, Steffen LM, Levey AS, Miller ER, et al. DASH (dietary approaches to stop hypertension) diet and risk of subsequent kidney disease. Am J Kidney Dis. 2016;68(6):853-61.

11 Tirosh A, Golan R, Harman-Boehm I, Henkin Y, Schwarzfuchs D, Rudich A, et al. Renal function following three distinct weight loss dietary strategies during 2 years of a randomized controlled trial. Diabetes Care. 2013; 36(8):2225-32.

12 Look AHEAD Research Group. Effect of a long-term behavioural weight loss intervention on nephropathy in overweight or obese adults with type 2 diabetes: a secondary analysis of the Look AHEAD randomised clinical trial. Lancet Diabetes Endocrinol. 2014;2(10): 801-9.

13 Díaz-López A, Bulló M, Martínez-González MÁ, Guasch-Ferré M, Ros E, Basora J, et al. Effects of Mediterranean diets on kidney function: a report from the PREDIMED trial. Am J Kidney Dis. 2012;60(3):380-9.

14 Díaz-López A, Babio N, Martínez-González MA, Corella D, Amor AJ, Fitó M, et al. Mediterranean diet, retinopathy, nephropathy, and microvascular diabetes complications: a post hoc analysis of a randomized trial. Diabetes Care. 2015;38(11):2134-41.

15 Martínez-González MA, Buil-Cosiales P, Corella D, Bulló M, Fitó M, Vioque J, et al. Cohort profile: design and methods of the PREDIMED-Plus randomized trial. Int J Epidemiol. 2019 Apr 1;48:387-8o.
16 Salas-Salvadó J, Díaz-López A, Ruiz-Canela M, Basora J, Fitó M, Corella D, et al. Effect of a lifestyle intervention program with energyrestricted Mediterranean diet and exercise on weight loss and cardiovascular risk factors: one-year results of the PREDIMED-Plus trial. Diabetes Care. 2019;42:777-88.

17 Alberti KGMM, Eckel RH, Grundy SM, Zimmet PZ, Cleeman JI, Donato KA, et al. Harmonizing the metabolic syndrome: a joint interim statement of the International Diabetes Federation Task Force on Epidemiology and Prevention; National Heart, Lung, and Blood Institute; American Heart Association; World Heart Federation; International Atherosclerosis Society; and International Association for the Study of Obesity. Circulation. 2009 Oct 20;120:1640-5.

18 Estruch R, Ros E, Salas-Salvadó J, Covas MI, Corella D, Arós F, et al. Primary prevention of cardiovascular disease with a Mediterranean diet supplemented with extra-virgin olive oil or nuts. N Engl J Med. 2018;378(25):e34.

19 Schröder H, Fitó M, Estruch R, MartínezGonzález MA, Corella D, Salas-Salvadó J, et al. A short screener is valid for assessing Mediterranean diet adherence among older Spanish men and women. J Nutr. 2011;141(6): 1140-5.

20 Fernández-Ballart JD, Piñol JL, Zazpe I, Corella D, Carrasco P, Toledo E, et al. Relative validity of a semi-quantitative food-frequency questionnaire in an elderly Mediterranean population of Spain. Br J Nutr. 2010;103(12): 1808-16.

21 Molina L, Sarmiento M, Peñafiel J, Donaire D, Garcia-Aymerich J, Gomez M, et al. Validation of the REGICOR short physical activity questionnaire for the adult population. PLoS One. 2017;12:e0168148.
Weight-Loss Lifestyle Intervention and Kidney Function
Am J Nephrol 2021;52:45-58 DOI: $10.1159 / 000513664$ 
22 Martínez-González MA, López-Fontana C, Varo JJ, Sánchez-Villegas A, Martinez JA. Validation of the Spanish version of the physical activity questionnaire used in the Nurses' Health Study and the Health Professionals' Follow-up Study. Public Health Nutr. 2005; 8(7):920-7.

23 Levey AS, Stevens LA, Schmid CH, Zhang YL, Castro AF, Feldman HI, et al. A new equation to estimate glomerular filtration rate. Ann Intern Med. 2009;150(9):604-12.

24 Sayón-Orea C, Razquin C, Bulló M, Corella D, Fitó M, Romaguera D, et al. Effect of a nutritional and behavioral intervention on energy-reduced Mediterranean diet adherence among patients with metabolic syndrome: interim analysis of the PREDIMED-Plus randomized clinical trial. JAMA. 2019;322:148699.

25 Joffe M, Hsu C, Feldman HI, Weir M, Landis JR, Hamm LL. Variability of creatinine measurements in clinical laboratories: results from the CRIC study. Am J Nephrol. 2010;31: 426-34.

26 Sung KC, Ryu S, Lee JY, Lee SH, Cheong E, Hyun YY, et al. Urine albumin/creatinine ratio below $30 \mathrm{mg} / \mathrm{g}$ is a predictor of incident hypertension and cardiovascular mortality. J Am Heart Assoc. 2016;5(9):e003245.

27 Chang AR, Grams ME, Ballew SH, Bilo H, Correa A, Evans M, et al. Adiposity and risk of decline in glomerular filtration rate: metaanalysis of individual participant data in a global consortium. BMJ. 2019;364:k5301.

28 Rhee CM, Ahmadi SF, Kalantar-Zadeh K. The dual roles of obesity in chronic kidney disease: a review of the current literature. Curr Opin Nephrol Hypertens. 2016;25(3):208-16.
29 Estruch R, Martínez-González MA, Corella D, Salas-Salvadó J, Fitó M, Chiva-Blanch G, et al. Effect of a high-fat Mediterranean diet on bodyweight and waist circumference: a prespecified secondary outcomes analysis of the PREDIMED randomised controlled trial. lancet Diabetes Endocrinol. 2016;4(8):666-76.

30 Estruch R, Martínez-González MA, Corella D, Salas-Salvadó J, Ruiz-Gutiérrez V, Covas MI, et al. Effects of a Mediterranean-style diet on cardiovascular risk factors: a randomized trial. Ann Intern Med. 2006;145(1):1-11.

31 Chrysohoou C, Panagiotakos DB, Pitsavos C, Skoumas J, Toutouza M, Papaioannou I, et al. Renal function, cardiovascular disease risk factors' prevalence and 5-year disease incidence; the role of diet, exercise, lipids and inflammation markers: the ATTICA study. QJM. 2010;103:413-22.

32 Esposito K, Marfella R, Ciotola M, Di Palo C, Giugliano F, Giugliano G, et al. Effect of a Mediterranean-style diet on endothelial dysfunction and markers of vascular inflammation in the metabolic syndrome: a randomized trial. JAMA. 2004;292(12):1440-6.

33 Toledo E, Hu FB, Estruch R, Buil-Cosiales P, Corella D, Salas-Salvadó J, et al. Effect of the Mediterranean diet on blood pressure in the PREDIMED trial: results from a randomized controlled trial. BMC Med. 2013;11:207.

34 Salas-Salvadó J, Bulló M, Estruch R, Ros E, Covas MI, Ibarrola-Jurado N, et al. Prevention of diabetes with Mediterranean diets: a subgroup analysis of a randomized trial. Ann Intern Med. 2014;160(1):1-10.

35 Babio N, Toledo E, Estruch R, Ros E, Martínez-González MA, Castañer O, et al. Mediterranean diets and metabolic syndrome status in the PREDIMED randomized trial. CMAJ. 2014;186(17):E649-57.
36 Bharakhada N, Yates T, Davies MJ, Wilmot EG, Edwardson C, Henson J, et al. Association of sitting time and physical activity with CKD: a cross-sectional study in family practices. Am J Kidney Dis. 2012;60(4):583-90.

37 Lynch BM, White SL, Owen N, Healy GN, Chadban SJ, Atkins RC, et al. Television viewing time and risk of chronic kidney disease in adults: the AusDiab Study. Ann Behav Med. 2010;40(3):265-74.

38 Hawkins M, Newman AB, Madero M, Patel KV, Shlipak MG, Cooper J, et al. TV watching, but not physical activity, is associated with change in kidney function in older adults. J Phys Act Health. 2015;12(4):561-8.

39 Robinson-Cohen C, Katz R, Mozaffarian D, Dalrymple LS, de Boer I, Sarnak M, et al. Physical activity and rapid decline in kidney function among older adults. Arch Intern Med. 2009;169(22):2116

40 Peterson JC, Adler S, Burkart JM, Greene T, Hebert LA, Hunsicker LG, et al. Blood pressure control, proteinuria, and the progression of renal disease. The modification of diet in renal disease study. Ann Intern Med. 1995; 123(10):754-62.

41 Zheng CM, Wang JY, Chen TT, Wu YC, Wu $\mathrm{YL}$, Lin HT, et al. Angiotensin-converting enzyme inhibitors or angiotensin receptor blocker monotherapy retard deterioration of renal function in Taiwanese chronic kidney disease population. Sci Rep. 2019;9(1):2694.

42 von Scholten BJ, Ørsted DD, Svendsen AL, Persson F, Rossing P. The influence of pharmaceutically induced weight changes on estimates of renal function: a patient-level pooled analysis of seven randomised controlled trials of glucose lowering medication. J Diabetes Complicat. 2015;29(8):1146-51. 